\title{
ALGO MÁS ACERCA DE LA RELACIÓN ENTRE DERECHO Y MORAL
}

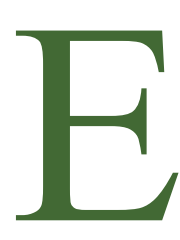

1 debate acerca de la relación entre derecho y moral tiene, como todos sabemos, una tradición milenaria. Comienza justamente en el momento en que se inicia la reflexión acerca de cuál es la denotación de la palabra «derecho». No existe prácticamente ningún jurista con un mínimo de interés por cuestiones filosóficas, que no haya intervenido en esta polémica. No es por ello aventurado suponer que ha de estar agotado el repertorio de los argumentos disponibles y que seguir hablando sobre este tema equivale a reiterar -en el mejor de los casos con diferentes acentos- lo ya dicho hasta el cansancio. Lo sensato entonces sería simplemente callar.

Sin embargo, el tema mismo ejerce una fascinación tal que siempre queda la esperanza justificatoria de poder formular algunas observaciones que contribuyan a precisar el estado de la cuestión y, sobre todo, a aclarar la propia posición. Probablemente por ello, uno abandona la vía del silencio y se lanza a decir algo más acerca de la relación entre derecho y moral.

Por lo pronto, pienso que no es aventurado afirmar que la innegable persistencia de la polémica se debe, por una parte, a los diversos puntos de vista que se adoptan para la definición del concepto de derecho y a los distintos significados que suele atribuirse a la palabra «moral», por otra. Ya hace casi tres décadas, Norberto Bobbio, al referirse a la polémica entre iusnaturalistas y iuspositivistas, observaba:

«las expresiones «iusnaturalismo»y «positivismo jurídico» han sido adoptadas con significados tan diversos que las relaciones entre las dos corrientes se colocan en diversos planos según que se trate de uno o de otro significado. [...] Precisamente por no tener en cuenta los diversos planos, se crea la curiosa consecuencia de que a menudo los argumentos de los adversarios no se encuentran y que después del duelo a muerte, ambos están más vivos que al principio.» (Norberto Bobbio 1962, en 1965, 67.) 
A su vez, la palabra «moral» puede ser utilizada para designar la moral positiva (en el sentido de John Austin 1954, 268), es decir, las mores de una determinada sociedad o de sus grupos dirigentes, o la moral crítica o ética.

En lo que sigue, deseo presentar algunas reflexiones sobre este tema, vinculadas con la relación entre los ordenamientos jurídicos existentes y la moral en su doble acepción.

La referencia a ordenamientos jurídicos existentes significa que habré de tomar en cuenta sólo el derecho tal como es y no como debería ser. Es decir, adoptaré una posición iuspositivista por lo que respecta a la teoría general del derecho y al modo de entender la ciencia del derecho. Sostendré, en cambio, que el positivismo jurídico no puede dar cuenta del funcionamiento real de los ordenamientos jurídicos positivos si rechaza no sólo la vinculación necesaria entre existencia del derecho positivo y moral en el sentido de mores sino también entre derecho y ética. Los argumentos que suelen ser esgrimidos en favor de la separación entre derecho y moral se basan principalmente en dos consideraciones: la primera de ellas es de tipo conceptual y sostiene que pretender incluir elementos morales en la definición del derecho significa una restricción inadmisible del campo de denotación de la palabra «derecho». Norbert Hoerster $(1889,10)$ llama a esta tesis la tesis de la neutralidad. Como es obvio, se aduce, que existen sistemas jurídicos injustos, si reservamos la palabra «derecho» sólo para referirnos a aquellos ordenamientos que no lo son, la única posibilidad que nos queda para designar regímenes jurídicos injustos es recurrir a expresiones plenas de carga emotiva tales como «injusticia institucionalizada», «dominación de la violencia» y otras similares.

Pero existe otro ámbito en el cual sería también relevante la distinción entre derecho y moral: es el de las consecuencias prácticas que de aquélla derivan. El rechazo de la tesis de la neutralidad atrofiaría la conciencia moral del individuo por lo que respecta a su evaluación del ordenamiento jurídico en el que vive y reforzaría consecuentemente las posibilidades de manipulación de la ciudadanía por parte de los gobernantes.

Para repensar esta cuestión, en lo que sigue habré de analizar estos dos tipos de argumentos. Por ello, he de considerar:

I) $\mathrm{Si}$ puede prescindirse de la vinculación entre derecho y moral (en sus dos versiones de moral positiva y crítica o ética) cuando se habla de ordenamientos jurídicos existentes. Mi conclusión será que ello es imposible.

II) Cuáles son las consecuencias prácticas que resultan de la aceptación o rechazo de la tesis de la separación entre derecho y 
moral. Esto significa enfrentarse con la cuestión de saber si la tesis de la neutralidad es éticamente la «más conveniente». Intentaré demostrar que la adhesión a esta tesis tiene implicaciones prácticas mucho menos relevantes que lo que suele suponerse.

I

En un artículo publicado recientemente, Philip Soper (1989) ha puesto de manifiesto que si se admite -como suelen hacerlo las teorías iuspositivistas de orientación hartiana- que «una teoría del derecho tiene que incluir una descripción de las pretensiones normativas formuladas por quienes aceptan o aplican el sistema jurídico», ello resulta inconsistente con una tesis central del positivismo jurídico, es decir, la que niega la existencia de una conexión necesaria entre derecho y moral:

«Dicho de otra manera, si el positivismo lleva a cabo coherentemente su proyecto de exponer las pretensiones normativas que las autoridades formulan con respecto al derecho, surge entonces un modelo en el cual la «esencia» del positivismo (la negación de la conexión necesaria entre derecho y moralidad) es incompatible con la «esencia» del derecho (una creencia justamente en tal conexión).» (Philip Soper 1989, 209.)

La línea argumentativa de Soper subraya la necesidad de vincular el enfoque de la teoría política con el de la teoría jurídica para poner de manifiesto la insostenibilidad de la tesis de la separación entre derecho y moral. Como, por mi parte, en un trabajo sobre el concepto de estabilidad de los sistemas políticos (Garzón Valdés, 1987), había propuesto partir de la teoría jurídica para lograr una mejor comprensión de la teoría política, justamente por lo que respecta a la relación entre moral y política, esta coincidencia -aunque en dirección contraria- con Soper me sugiere la conveniencia de seguir avanzando por esta misma vía.

Todo sistema jurídico existente (el único que, según el positivismo jurídico, merece la atención del científico del derecho) requiere como condición necesaria, aunque no suficiente, la adhesión a sus principios y normas por parte de las autoridades y funcionarios del sistema. Esto es lo que en la terminología de H. L. A. Hart es llamado «punto de vista interno», para distinguirlo del «punto de vista externo», es decir, de la actitud que adoptan frente al sistema quienes lo obedecen sólo por razones prudenciales o quienes observan desde afuera el sistema: 
«En todo momento de la vida de toda sociedad que vive bajo reglas, jurídicas o no, es probable que exista una tensión entre quienes, por una parte, aceptan y cooperan voluntariamente en el mantenimiento de las reglas y, por ello, juzgan su propio comportamiento y el de las otras personas en términos de las reglas, y, por otra, quienes rechazan las reglas y las siguen sólo desde el punto de vista externo, como señal de posible castigo.» (H. L. A. Hart 1961, 88.)

Quienes adhieren al sistema, es decir, quienes adoptan el punto de vista interno, lo hacen porque aceptan sus normas en tanto pautas de comportamiento. Como esta aceptación no puede, por definición, deberse a razones prudenciales (el temor a un posible castigo o la esperanza de obtener algún premio, por ejemplo), no parece aventurado afirmar que su fundamento ha de buscarse en la creencia de que las normas coinciden con los principios y reglas supremas de justificación y orientación del comportamiento que ellos sustentan. Por ello, la reacción frente a quienes no aceptan las reglas básicas del sistema ha de ser más fuerte que la de un mero juicio condenatorio por desobediencia. Para decirlo con palabras de Neil MacCormick (1981, 161):

«Cuando el mal es hecho en nombre del derecho, lo peor es que todo lo que se hace en nombre del derecho es inevitablemente hecho también en nombre de la moralidad pública. Por lo tanto, parece simplemente inconcebible que las apelaciones al derecho -aun cuando se trate de un derecho perverso- puedan echar por la borda su carga moral [...] [o] que no será considerado como algo virtuoso -por más que lo sea en un punto muy modesto de la escala de la virtud- el que una persona obedezca el derecho, aun cuando el derecho que ella obedece contenga mucho de malo. Por la misma razón, quien viola el derecho, por más grande que pueda ser su conciencia moral, será siempre estigmatizado por las autoridades legales como un delincuente moral y como un peligro moral.»

Por supuesto que alguien podría sostener que esta afirmación es exagerada y que la parte oficial se limita a la aplicación de las normas válidas, sin necesidad de recurrir a otro criterio de validez como no sea el del respeto de un procedimiento fijado en la Constitución. Esto puede ser verdad a primera vista en muchos casos, pero lo que no puede negarse es que siempre es posible preguntar a la parte oficial por qué considera que debe obedecerse lo que establece la Constitución, es decir, por qué considera que la Constitución es válida. Las explicaciones puramente procedimentales como las propuestas por Niklas Luhmann (cfr. por ejemplo, 1975, 37) no me parecen satisfactorias, como ya lo 
he expuesto en otro lugar (cfr. Garzón Valdés, 1987, 7). Así pues, si la persona a quien se dirige la pregunta no quiere cometer falacia alguna y, además, desea superar las limitaciones del enfoque procedimental, tendrá que recurrir a alguna explicación normativa. Si, además, rechaza las apelaciones de tipo teológico, tendrá necesariamente que invocar argumentos tales como «porque lo que establece la Constitución es correcto». El criterio de esta corrección tendrá, pues, que ser extrajurídico y estar colocado a un nivel tal que sirva como justificación última. Este tipo de justificaciones es precisamente lo que suele llamarse justificaciones morales.

Porque ello es así, quienes adoptan el punto de vista interno (es decir, por lo pronto, los legisladores y funcionarios; dicho brevemente: la parte oficial) sostendrán que su sistema coincide con la moral, también en el sentido fuerte de la palabra, es decir, como ética. Pues es obvio que quienes adhieren internamente a las normas lo hacen porque consideran que ellas son las «verdaderamente» correctas. La distinción hartiana entre «tener una obligación» y «sentirse obligado» tiene sentido sólo si se admite que quienes afirman tener una obligación lo hacen porque piensan que las normas que la imponen son las correctas, también desde el punto de vista ético. Si se recuerda la distinción propuesta por Ingemar Hedenius (1981, 122 sigs.) entre «proposiciones morales internas» y «externas», puede decirse que la expresión del punto de vista interno es siempre también una «proposición moral interna» con la que las autoridades y funcionarios del sistema jurídico manifiestan su creencia en la corrección ética del sistema. Esto es lo que Max Weber llamaba «creencia en la legitimidad» y a lo que el politicólogo Seymour M. Lipset (1959, 86 sig.) se refiere cuando afirma que «los grupos considerarán a un sistema político como legítimo o ilegítimo de acuerdo con la forma como sus valores [los del sistema, E. G. V.] coincidan con sus valores primarios».

Sin embargo, podría insistirse en la tesis de la separación y sostener que todo esto no tiene nada que ver con actitudes morales de la parte oficial del sistema. Uno de los autores que con mayor vehemencia ha sostenido últimamente la tesis de la separación desde una perspectiva hartiana es Rolf Sartorius. Conviene por ello detenerse en la consideración de su argumento central: si la parte oficial simplemente hace cumplir las reglas válidas de acuerdo con la regla de reconocimiento y los ciudadanos en su mayor parte las obedecen «puede decirse que el sistema jurídico existe»; el aspecto volitivo de adhesión a las normas básicas del sistema no sería necesario: 
«Consideremos un sistema jurídico en el que la parte oficial satisface la condición de conformidad y las condiciones de creencia acerca de las preferencias, los sentimientos y las creencias de los demás pero en el cual las creencias son de hecho falsas. Cada miembro de la parte oficial puede, en el fondo de su corazón, rechazar los valores que abraza el sistema y desear su derrumbe pero (creyendo equivocadamente que [por ejemplo] los otros miembros de la parte oficial son buenos nazis) continuar el «juego» de imponer las reglas del sistema [...] básicamente por miedo.» (R. Sartorius, 1987, 51 sig.)

Este sería el caso de un país en el que toda la parte oficial tiene una percepción equivocada de las razones que motivan el comportamiento de sus integrantes y en donde todos ellos, además, rechazan internamente el sistema. No puede negarse que esta situación ofrece un buen argumento para una tragicomedia de errores. El país en el que esto ocurriera podría ser denominado (recurriendo a la raíz germánica irr (de donde deriva Irrium, error): Irrlandia.

Desde luego, esta denominación sólo podría ser dada por un observador extranjero que observara el error en que se encuentran las autoridades de Irrlandia al imputarse recíprocamente creencias equivocadas. Bastaría en ese caso que este observador, con un mínimo de benevolencia, desvelara este error colectivo para que el sistema se derrumbara de inmediato. La estabilidad del sistema hasta ese momento habría requerido, además, que ninguno de los ciudadanos se hubiera atrevido a sacar a la parte oficial del error en que se encontraba, a pesar de que ello los hubiese liberado de un régimen que ellos rechazaban. La raíz germánica podría ser aquí también instructiva, ya que de ella deriva igualmente Irre (loco). Irrlandia se convierte entonces en Delirandia.

Una versión más suave de Irrlandia -y que también sugiere Sartorius- es Apatilandia. En este país, la parte oficial no padece los efectos de la creencia errónea sino que no tiene ninguna creencia acerca del valor de las reglas básicas del sistema: simplemente las cumple por hábito, tradición o aburrimiento. En este caso, se aducirá, no puede hablarse en absoluto de una adhesión a las reglas del sistema en sentido fuerte como es el que requiere la adhesión moral.

Hart (1958, 92 sig.) parece haber pensado en la posibilidad de Apatilandia cuando afirma:

«[T] anto la obediencia general y el ulterior uso de y las actitudes frente a la ley pueden ser motivadas por temor, inercia, admiración de la tradición, o cálculo a largo plazo de intereses egoístas como así 
también por el reconocimiento de una obligación moral. [...] La cuestión acerca de qué es lo que motiva la práctica, aunque importante, es una cuestión independiente.» (Subrayado de E. G. V.)

Pero para que la inercia pudiera explicar (si es que ello es posible) la existencia de una regla de reconocimiento en Apatilandia, habría que agregar que en ese país Nadie sustenta creencia alguna acerca de cómo deberían ser las reglas que orientan el comportamiento colectivo, ya que si así no fuera, no podría evitarse una confrontación entre sus creencias acerca de lo que debe ser con lo que efectivamente es. Los apatilandios no tienen que haberse planteado nunca, en ninguno de sus estratos sociales, la pregunta acerca de por qué actúan como actúan.

Estos contraejemplos supuestamente empíricos son una respuesta a la situación imaginada por Sartorius quien invoca en su defensa al propio Hart (1961, 198 sig.):

[Una] condición necesaria para la existencia de un poder coactivo es que algunos al menos tienen que cooperar en el sistema y aceptar sus reglas [...] pero, no es[...] verdad que aquellos que aceptan el sistema voluntariamente tengan que concebirse a sí mismos como moralmente obligados a hacerlo [...] En realidad, su adhesión al sistema puede estar basada en muchos cálculos diferentes: cálculos de interés a largo plazo; falta de interés en los demás; y actitudes heredadas o tradicionales no reflexionadas; o el simple deseo de actuar como los demás. En verdad, no hay razón por la cual quienes aceptan la autoridad del sistema deberían no examinar su conciencia y decidir que, moralmente, no deberían aceptarla; sin embargo, por una variedad de razones, continúan haciéndolo.»

La cita es buena pero resulta difícil de conciliar con la siguiente afirmación, también de Hart $(1961,56)$ :

«Lo que es necesario es que haya una actitud crítica reflexiva con respecto a ciertas pautas de comportamiento como un criterio común y que esto se manifieste en crítica (incluyendo la autocrítica), en pedidos de conformidad y en el reconocimiento de que tal crítica y exigencias están justificadas, todo lo cual encuentra su expresión característica en la terminología normativa de ?debe", ?tiene que" y ?debería", ?correcto", ?falso".»

Si quienes adoptan el punto de vista interno asumen también una actitud crítica y autocrítica, no se ve muy bien cómo podría incluirse a las autoridades apatilandesas en esta categoría.

Sartorius $(1987,47)$ reconoce, por otra parte, que «Hart no intenta asociar el aspecto interno de la existencia de las normas 
con aquellos que las aceptan sintiéndose obligados a seguirlas». Pero entonces no se entiende el caso de los jueces no nazis del ejemplo de Sartorius ya que ellos sí se sienten obligados a obedecer las normas nazis por temor a la reacción de los otros jueces supuestamente nazis. Los jueces de Irrlandia dirían seguramente que ellos «se sienten obligados a actuar así» que «probablemente sufrirán algún castigo o represalia si no lo hacen». Pero este tipo de razones son justamente las que corresponden al punto de vista externo (cfr. H. L. A. Hart 1961, 88).

Sea como sea, en los casos de Irrlandia y Apatilandia, me he referido a la inestabilidad estructural de estos sistemas, pero he presupuesto también la posibilidad de su existencia (por más improbable que ella pueda ser). Sin embargo, la tesis que deseo sostener es más fuerte: entre derecho y moral existe una relación conceptual, es decir, el sistema jurídico no puede existir sin la pretensión de corrección moral de su regla de reconocimiento.

Theodor Viehweg ha señalado reiteradamente (cfr. especialmente T. Viehweg, 1960) que ninguna sociedad puede mantener su cohesión si no cuenta con una estructura jurídica que establezca dogmáticamente qué es lo que en ella se considera justo. Todo jurista práctico, tanto en su función interpretativa como legislativa, está sujeto a esta estructura dogmática, que es justamente la que posibilita la convivencia al permitir la coordinación de las acciones de los individuos que integran un colectivo cualquiera. La parte oficial del sistema jurídico es la que se encarga primordialmente de hacer valer la intentio dogmatica del derecho, cuya corrección no puede poner en tela de juicio.

Esta intentio dogmatica suele ser curiosamente desplazada a segundo plano hasta por los más lúcidos representantes de la tesis de la neutralidad. Tal es el caso de Norbert Hoerster, quien considera $(1989,21)$ como caracterización suficiente de las normas jurídicas la siguiente:

«1. Estas normas han sido creadas de acuerdo con una Constitución nacional que posee vigencia en la sociedad. 2. Estas normas son parte de un orden normativo que prevé la aplicación de la coacción física llevada a cabo regularmente por los funcionarios competentes. De aquí se sigue 3. quien se niegue a obedecer estas normas tendrá que contar con las consecuencias amenazadas.»

Hoerster se refiere obviamente a normas vigentes en un Sistema existente y no a proyectos de sistemas jurídicos. Pero, en este caso, al concepto de «funcionario competente» pertenece la pretensión de autoridad y al de «Constitución vigente» la inten- 
tio dogmatica. Por ello, puede afirmar Gerald J. Postema (1987, 92 sig.):

«La propiedad que distingue al derecho de otros ejercicios del poder social es que el derecho -o más bien la parte oficial- pretende autoridad para la formulación de sus directrices lo mismo que para respaldarlas con la amenaza de la fuerza. Nos vemos forzados a negar hasta de facto autoridad a los imperativos respaldados por la fuerza si aquellos que los formulan no pueden pretender legitimidad sin contradicción o autoengaño. [...] Si (la parte oficial, E. G. V.) no puede pretender legitimidad para ella misma, no tenemos base sobre la cual podamos acordarle, ni siquiera de facto, legitimidad. Pero, entonces, hay un sentido directo en el cual la fuerza coactiva institucionalizada no puede ser considerada como derecho.» $(1987,93)$.

Vistas así las cosas, quien sostenga la tesis de la neutralidad, se ve enfrentado con un doble problema: en primer lugar, si acepta que la validez de las normas del sistema (inclusive la Constitución) depende de su coincidencia con los criterios establecidos en última instancia por una regla de reconocimiento (algo que admitiría probablemente Hoerster) tendrá que aceptar también que conceptualmente ella está vinculada con el punto de vista interno de, al menos, la parte oficial del sistema, es decir, de su adhesión a esa regla por razones no prudenciales; segundo, si quiere describir qué es lo que realmente hacen quienes dictan y aplican el derecho, no puede dejar de tomar en cuenta la pretensión de corrección normativa que sustentan estas personas, que no puede basarse, en última instancia, en una especie de mandato presupuesto, moralmente neutro, que obligaría a obedecer la Constitución si es que no se quiere caer en las conocidas dificultades de una norma básica de tipo kelseniano.

Como es sabido, la tarea que se impuso Hart en su crítica a la teoría imperativa tal como fuera formulada por Bentham y Austin era doble: por una parte, explicar la normatividad del derecho y, por otra, mantener la separación conceptual entre derecho y moral. Para esto último, insistió en la necesidad de considerar que expresiones tales como «obligación», «deber», «derechos» tienen un significado diferente en contextos jurídicos y morales. Con respecto a lo primero, la solución que propuso fue distinguir entre punto de vista interno y punto de vista externo. Sobre esta base, pudo distinguir también entre enunciados internos (o «comprometidos», «committed») y externos (o «informes», «reports»). Posteriormente, en su trabajo sobre Bentham (cfr. H. L. A. Hart, 1982), introdujo una tercera categoría intermedia: los enunciados «desprendidos», no comprometidos («de- 
tached»). Estos últimos son enunciados que se formulan desde el punto de vista de quien acepta la validez de las normas sin comprometerse; podrían ser considerados como la expresión de una aceptación en sentido débil. Con esto quería subrayar la diferencia entre obligación jurídica y obligación moral, ya que quienes formulan enunciados «desprendidos» no tienen porqué adherir al contenido de la norma en cuestión y, sin embargo, pueden formular enunciados de obligación.

Esta puede ser una forma adecuada de exponer la actitud que en muchos casos asumen los jueces; no tiene nada de insólito que un juez pronuncie una sentencia conforme a la ley vigente, aun cuando no adhiera internamente al contenido de la misma. La ley le ofrecería lo que Hart llama «razones jurídicas vinculantes», que son perentorias e independientes de su contenido. Pero, lo importante es saber si estos enunciados no comprometidos pueden darse sin el apoyo de los comprometidos, es decir, los formulados desde un punto de vista interno, con sus connotaciones morales. Pienso que ello es imposible.

Dentro de ciertos límites, en el caso de los jueces, probablemente Hart tenga razón en el sentido de que cuando aplican el derecho no tienen porqué suponer la legitimidad moral de la legislatura:

«Así los jueces individuales pueden explicar o justificar su aceptación de las disposiciones del legislador diciendo que ellos desean continuar una práctica establecida o que, al asumir su cargo, han jurado continuarla o que ellos han aceptado tácitamente hacerlo al aceptar el cargo de juez. Todo esto sería compatible con jueces que, o bien no tienen ninguna creencia con respecto a la legitimidad moral de la legislatura o hasta creen que ésta no tiene ninguna.» (H. L. A. Hart, 1982, 265.)

$\mathrm{Y}$ hasta podría admitirse que algunos legisladores prestan su consentimiento a ciertas leyes, aun cuando estén convencidos de su incorrección moral. Lo hacen por lealtad partidista o por el temor a perder su mandato, es decir, por razones prudenciales. Pero, el problema consiste en saber si esta actitud puede conceptualmente ser generalizada. El concepto mismo de razones perentorias es dependiente de la atribución de autoridad a quien las formula, y quien se presenta como autoridad última del sistema no puede invocar -so pena de caer en un círculo vicioso razones perentorias sino que tiene que adherir en sentido fuerte al contenido de sus normas, es decir, otorgarles su aprobación moral. 
Si esto es así, puede inferirse que no es posible excluir del concepto de derecho (existente, positivo) su vinculación con la moral, si es que se lo quiere entender tal como es y como funciona en la realidad.

En efecto, como lo he señalado más arriba, quienes adoptan el punto de vista interno, sólo pueden explicar la validez última de las normas del sistema recurriendo a argumentos morales, que para ellos se identifican con argumentos éticos. Dicho en términos de la teoría política: para ellos, legitimación coincide con legitimidad, entendida esta última como coincidencia de las normas del sistema con los principios de la ética.

Por ello, el punto de vista interno puede ser llamado también «pretensión de legitimidad», es decir, que quien lo adopta formula una pretensión de corrección ética. Con la pretensión de legitimidad sucede lo mismo que con la pretensión de verdad que sustenta quien afirma creer en la verdad de una proposición descriptiva. Es obvio que quien cree en la verdad de $P$ considera que $P$ es verdadera. Desde el punto de vista de la persona que sustenta una creencia, creencia y verdad coinciden. Por ello, podía afirmar Ludwig Wittgenstein (1960, 500):

«Si existiera un verbo con el significado ?creer falsamente", no tendría sentido la primera persona del indicativo ?creo..., y no es así" sería una contradicción.»

Con respecto a la pretensión de legitimidad y la relación entre moral y ética, la observación de Wittgenstein podría ser parafraseada de la siguiente manera:

Es contradictorio afirmar:

«Creo en la legitimidad de mi sistema, pero es ilegítimo.»

$\mathrm{O}$ :

«Creo en la legitimidad de mi sistema, pero no pretendo que lo sea.»

$\mathrm{O}$ :

«Creo que la regla de reconocimiento coincide con mis valoraciones primarias, pero es incorrecta moralmente.»

$\mathrm{O}:$

«Mi posición moral es éticamente incorrecta.»

Ante frases como éstas, a más de una desconcertante sorpresa, no dejaríamos de sentir una cierta satisfacción etnológica por haber descubierto finalmente auténticos irrlandeses.

Desde un enfoque algo diferente, Robert Alexy $(1989,177)$ se ha referido a la «pretensión de corrección», como un «elemento necesario del concepto de derecho. Ella establece la conexión 
entre derecho y moralidad». Para ilustrarla, recurre al siguiente ejemplo: supongamos que en un Estado X una asamblea constitucional resuelve incluir en el artículo primero de la Constitución la siguiente frase:

$X$ es una república soberana, federal e injusta.

Sin duda, este artículo es manifiestamente defectuoso. Pero, el defecto no es técnico, moral o convencional sino conceptual:

«Con el acto de dictar una Constitución está necesariamente conectada una pretensión de corrección, en este caso, una pretensión de justicia. El autor de una Constitución comete una contradicción performativa si el contenido de su acto constitucional niega esta pretensión, mientras que la plantea con la ejecución de su acto.» (R. Alexy, 1989, 179.)

Pretensión de legitimidad, pretensión de corrección o pretensión de autoridad (fórmula utilizada por Philip Soper, loc. cit.) son expresiones sinónimas que indican la vinculación conceptual entre derecho y moral. Así como Hoerster $(1989,22)$ afirma que hablar de derecho positivo es un mero pleonasmo, podría decirse que hablar de autoridad con pretensión de autoridad o de legitimidad también lo es.

Por supuesto que sostener esto no tiene nada que ver con la afirmación de criterios seguros para determinar la validez «objetiva» de los juicios morales o para juzgar la corrección moral de estas pretensiones. Pero, el observador externo que analiza el sistema jurídico en cuestión, sólo podrá explicar totalmente la validez de sus normas si recurre a las convicciones extrajurídicas (morales) de quienes la dictan y aplican. Y, desde luego, puede suceder aquí que el observador no acepte la concepción moral de las autoridades y funcionarios por considerar que ella viola principios éticos. Desde el punto de vista del observador externo, siempre es posible establecer una distinción entre legitimación y legitimidad, de la misma manera que es posible hacerlo con respecto a la creencia de verdad de un tercero. Es obvio que sus «proposiciones morales internas» pueden no coincidir con las de quienes aceptan e imponen el sistema objeto de su consideración. Pero, de aquí no se sigue sin más que necesariamente deba negar el carácter de jurídico al sistema que considera. De la negación de la tesis de la neutralidad no se sigue que no pueda calificarse a un sistema jurídico existente como inmoral.

Dicho con otras palabras: las autoridades y funcionarios se 
contradirían a ellos mismos si sostuvieran que la ética no juega ningún papel en el concepto de validez de las normas frente a las que adoptan un punto de vista interno; a su vez, el observador, en nuestro caso el científico del derecho, tampoco podría dar cuenta de los prerrequisitos de la existencia de un sistema jurídico si negara su fundamento último en la moral positiva sustentada por la parte oficial del sistema, que para ella coincide con la ética. En cualquiera de los dos casos resulta pues falsa la separación de derecho y moral a nivel conceptual.

La citada caracterización de Hoerster de las normas jurídicas parece ser muy similar a la de Bentham y deja sin explicar la normatividad de los enunciados de obligación jurídica. Ya Hart (1982, 144 sig.) lo había visto claramente:

«Decir que una persona tiene una obligación jurídica de realizar un cierto acto no es, a pesar de que pueda implicarlo, un enunciado acerca del derecho o un enunciado que dice que existe una ley que le exige que se comporte de cierta manera. Es más bien evaluar su actuación o no actuación desde el punto de vista adoptado al menos por los tribunales del sistema jurídico que aceptan el derecho como una pauta de guía y evaluación de la conducta, determinando lo que es permisible mediante exigencias y presión de conformidad. Tales enunciados no son enunciados históricos o fácticos que describen acciones pasadas, presentes o futuras [...] [son] enunciados normativos. [...] Muchos intentos se han realizado para «reducir» los enunciados normativos a proposiciones históricas o fácticas [...] tales esfuerzos han fracasado $[\ldots]$

Creo que esta última frase vale también para los intentos de explicar la normatividad sin recurrir a la pretensión de autoridad, de legitimidad o de corrección de la parte oficial del sistema, pretensión que no puede basarse circularmente en consideraciones prudenciales o pender en el aire de la apatía o del hábito no reflexionado. La fidelidad a la tesis de la neutralidad trae los problemas que he intentado señalar y sugiere la conclusión de que Hart no puede solucionar satisfactoriamente el problema de la normatividad del derecho si insiste en mantener esta tesis.

Resumiendo, podría decirse que, a nivel descriptivo, la tesis de la neutralidad puede tener alguna de estas dos formulaciones: a) la moral positiva no juega ningún papel en el concepto de derecho, o $b$ ) la ética no juega ningún papel en el concepto de derecho.

Lo que he tratado de sostener aquí es que, desde el punto de vista de la mayor parte de las autoridades y funcionarios (salvo 
los casos de IrrIandia y Apatilandia), las versiones a) y b) son falsas y que desde el punto de vista del observador, por lo menos la versión $a$ ) es falsa.

Pero podría ahora pensarse en el caso de un defensor de la tesis de la neutralidad que, dejando de lado los problemas conceptuales aquí tratados, sostuviera que la tesis de la conexión entre derecho y moral es peligrosa en virtud de las consecuencias prácticas que de ella derivan. A este punto quiero ahora referirme.

\section{II}

Uno de los argumentos fuertes en favor de la separación entre derecho y moral es el que sostiene que esta última no debería jugar ningún papel en la definición de derecho, justamente por razones éticas. Dejando de lado las dificultades que ello implica de acuerdo con lo expuesto en la sección anterior, quiero ahora considerar esta argumentación por separado.

La he calificado de fuerte porque suele invocar a su favor algo que no cuesta aceptar como principio básico de la ética, es decir, el respeto de la autonomía de las personas en el sentido de seres capaces de adoptar evaluaciones personales con respecto al deber de obediencia de las normas jurídicas. Para decirlo con palabras de H. L. A. Hart (1961, 205 sig.):

«Mientras los seres humanos puedan obtener suficiente cooperación de algunos de forma tal que les permita dominar a otros, usarán las formas del derecho como uno de sus instrumentos. Hombres malvados dictarán reglas malvadas que otros aplicarán. Lo que seguramente más se necesita a fin de lograr que las personas sean perspicaces cuando se ven confrontadas con el abuso oficial del poder es que ellas conserven el sentido de que la certificación de que algo es jurídicamente válido no es concluyente con respecto a la cuestión de la obediencia y que, por más grande que pueda ser el aura de majestad o autoridad que el sistema oficial pueda tener, sus exigencias tienen, en última instancia, que ser sometidas a examen moral.»

Los peligros de la confusión entre «derecho» y «justicia» fueron también subrayados por Hans Kelsen (1948, 383):

«Tiene el efecto que todo derecho positivo [...] ha de ser considerado a primera vista como justo ya que se presenta como derecho y es generalmente llamado derecho. Puede ser dudoso que merezca ser llamado derecho, pero tiene el beneficio de la duda. Quien niegue la 
justicia de tal «derecho» tiene que probarlo; y esta prueba es prácticamente imposible ya que no hay un criterio objetivo de la justicia. Por lo tanto, el efecto real de la identificación terminológica de derecho y justicia es una justificaciónilícita de cualquier derecho positivo.»

Tanto en el caso de Hart como en el de KeIsen, no hay duda que la insistencia en mantener la tesis de la separación se debe a razones morales. Justamente porque ambos juristas eran «moralistas críticos», como diría Neil MacCormick (1981, 169), ambos sostenían la conveniencia de eliminar del concepto de derecho toda referencia a su moralidad. Sobre la afirmación de Kelsen acerca de la imposibilidad de contar con criterios objetivos de justicia, volveré más adelante.

Ahora me interesa señalar que a esta concepción parece subyacer no sólo el temor a una justificación ¡lícita de los ordenamientos jurídicos sino también -y esto es mucho más importante- la creencia de que el rechazo de la tesis de la separación destruye, o al menos reduce, la capacidad crítica de los ciudadanos. Dicho con otras palabras: se supone una vinculación de correlación entre la obligación impuesta por la parte oficial, de acuerdo con sus creencias morales, y la creencia en el deber moral de obediencia de estos mandatos por parte de los ciudadanos.

Como se ha visto más arriba, la parte oficial, sean sus integrantes iusnaturalistas o iuspositivistas, sostendrá, por lo general, que las normas del sistema que ella dicta o aplica son moralmente correctas.

Como contraargumento, podría recordarse la frase que Gustav Radbruch incluyera en la 3. ${ }^{a}$ edición de su Rechtsphilosophie (1932):

«El juez tiene la obligación profesional de hacer valer la voluntad de validez de la ley, sacrificar el propio sentimiento jurídico ante la orden autoritaria del derecho, preguntar únicamente qué es lo que es derecho y nunca si también es justo. [...] Despreciamos al párroco que predica en contra de sus convicciones, pero honramos al juez que no se deja engañar en su fidelidad a la ley por una sensibilidad jurídica contraria a aquélla.» (op. cit. 83.)

En su hora, esta frase escandalizó a los iusnaturalistas debido al énfasis que Radbruch ponía en la superioridad del mandato legal, en lo que Hart llamaría después «razones perentorias», sobre los dictados de la conciencia del juez. Pero, si se acepta que los jueces integran la parte oficial del sistema jurídico y que, por lo tanto, asumen, por lo general, un punto de vista interno con 
las connotaciones morales ya señaladas, podría sostenerse, desde una perspectiva iuspositivista, que lo que molesta en la afirma ción radbruchiana es justamente la contradicción que existe entre la adhesión por parte del juez a las reglas del sistema y la concepción moral que este mismo juez sustenta. Hay aquí una contradicción entre las proposiciones que expresan su «punto de vista interno» y sus «proposiciones morales internas». En este sentido, la actitud de desprecio frente a este juez podría estar plenamente justificada, en contra de lo que suponía Radbruch. No se necesita ser iusnaturalista para tener serias dudas no sólo acerca de la integridad moral de este juez sino de su coherencia pragmática.

En cuanto a los ciudadanos, puede suceder que ellos adopten un punto de vista interno o un punto de vista externo con respecto a los mandatos de la parte oficial. En el primer caso, coincidirán con ellos también en sus «proposiciones morales internas»; en el segundo, por definición, no aceptarán la corrección moral de las imposiciones y su obediencia habrá de deberse a razones prudenciales, sean ellos partidarios del iusnaturalismo o del iuspositivismo.

Rudolf Laun $(1935,15)$ afirmaba:

«El individuo tiene, por consiguiente, frente al llamado derecho positivo [...] una doble posibilidad: o bien lo aprueba, lo vive en el caso singular de aplicación como deber ser, como exigencia última de su conciencia o de su sentimiento jurídico -en este caso es para él derecho, aun cuando no lo obedezca-, o falta esta aprobación y entonces es para el individuo sólo fuerza violenta, aun cuando se incline ante ella. No existe una tercera posibilidad.»

Esta observación empírica es obviamente verdadera. Me inclino, en cambio, a creer que es falso sostener que exista una relación causal entre la posición (iusnaturalista o iuspositivista) que adopte la parte oficial y la actitud de aprobación o rechazo de sus normas por parte de los ciudadanos. Al respecto, pienso que tienen interés las siguientes consideraciones de Samuel I. Shuman (1963, 207):

«Si la moderna filosofía del derecho ha de ser acusada políticamente por haber jugado algún papel en los recientes flagelos de la historia, parecería que la acusación presenta un dilema: primero, el recurso a las doctrinas del derecho natural si bien es cierto que puede conducir a una mayor resistencia contra los totalitarismos, también conduce a la disminución de la responsabilidad moral y política del individuo. Segundo, el positivismo jurídico, si bien es cierto que 
vuelve ineludible la responsabilidad individual, quizás espera demasiado de las fuerzas no lógicas de la persona y al dejarlas sin conducción promueve su extravío. No es obvio que deba preferirse la segunda alternativa; pero que deba preferirse la primera es algo que se me presenta como política y moralmente contraproducente. En efecto, el positivismo jurídico, al argumentar en favor de la separación entre derecho y moral, elige la segunda alternativa y revela así al menos parte de su «fundamento moral y emocional», la creencia en la posibilidad de la responsabilidad individual que sirve como baluarte adecuado en contra de los tipos de abusos jurídicos que permiten el surgimiento de un Estado nacional. [...] Por el contrario, el derecho natural, al aceptar la primera de las dos alternativas mencionadas más arriba, desea asegurar que se lleve a cabo la decisión adecuada proporcionando de antemano una versión de la naturaleza del mundo real (jurídico) que incluye ya el esperado comprometimiento valorativo. Al proceder así, el derecho natural revela que su ?fundamento moral y emocional" es la creencia en la incapacidad de tomar las decisiones correctas.»

He presentado esta larga cita porque creo que ella expresa de manera muy clara el argumento de la ventaja ético-pedagógica de la opción por la tesis de la separación y el peligro que puede implicar dotar de un halo de moralidad al derecho positivo. Conviene por ello considerar más de cerca el fundamento de la misma.

Por lo pronto, si bien es correcto sostener que desde el punto de vista moral todo ordenamiento jurídico debe ser sometido al juicio crítico individual, no cuesta encontrar contraejemplos históricos que permiten poner en duda la corrección de la tesis según la cual habría una relación causal entre iusnaturalismo o iuspositivismo y el comportamiento ciudadano. En la larga lista de los cómplices de las dictaduras, se encuentran tanto iusnaturalistas como iuspositivistas y los períodos de vigencia de una u otra posición no coinciden con los resultados esperados o temidos por los filósofos del derecho. El nacionalsocialismo contó tanto con la bendición filosófica de los «iusnaturalistas» Karl Larenz y Hans Helmut Dietze como con la adhesión «iuspositivista» de los jueces que se guiaban por «razones perentorias».

Por las razones expuestas en la primera parte de este trabajo, la parte oficial procurará siempre conferir un halo de moralidad a sus normas y sostendrá que ellas son justas y, por lo tanto, «verdadero derecho». Puede hasta negar tal carácter a los sistemas jurídicos opuestos y autocalificarse, si se quiere, de «iusnaturalista». Pero de aquí no se infiere que esta actitud tenga necesariamente que provocar una obediencia ciudadana ciega. El 
resultado no sería tampoco muy diferente si la parte oficial se autocalificara de «iuspositivista» y sostuviera que, a pesar de que sus normas, por definición, no están vinculadas con la moral y que hay que distinguir entre obligación jurídica y obligación moral, ellas tienen que ser obedecidas por haber sido dictadas de acuerdo con un determinado procedimiento y estar respaldadas por sanciones. La equivocada creencia en una relación causal entre iuspositivismo y obediencia a la ley provocó en la Alemania de la inmediata posguerra una estéril polémica que no es aconsejable reiterar.

Y una última consideración: Como hemos visto, Hans Kelsen pensaba que no era posible ofrecer un criterio objetivo de justicia y, por lo tanto debía rechazarse la posición iusnaturalista. En tanto relativista, Kelsen sostenía la imposibilidad de lograr -sin caer en absolutismos metafísicos o teológicos- una fundamentación de las normas morales aceptable universalmente. Pienso que la alternativa kelseniana es demasiado radical. Cabría la posibilidad de un objetivismo ético que aceptara, como punto de partida, el deber de satisfacer las necesidades básicas (naturales y derivadas) de las personas dentro del marco de la mayor libertad individual posible. Esta es la vía sugerida por Mario Bunge (1989) y Ruth Zimmerling (1989).

Pero si ello parece problemático, podría tomarse como criterio objetivo -en el sentido de una aceptación intersubjetiva, propuesto por el propio Kelsen- las declaraciones universales de derechos humanos suscritas por todos los Estados del mundo. En ellas se hace referencia también a normas suprapositivas, sin que esto implique una fundamentación metafísica, sino mas bien la aceptación de una estructura hipotética y presuntiva de los derechos humanos en tanto axiomas no derivables que constituyen un metasistema normativo y regulan el contenido de las normas de los sistemas jurídicos positivos. Esta es la posición, por ejemplo, de Ulrich Klug (1989, 24 sigs.).

Sea cual sea la vía que se elija, no parece desacertado sostener que las posiciones que postulan una separación entre derecho y moral se ven enfrentadas con serios problemas, tanto a nivel conceptual como práctico. Además, sobre el iuspositivismo, entendido como ideología de la justicia, pesan todos los inconvenientes vinculados con un relativismo ético radical, cuyo tratamiento supera, desde luego, los límites de este trabajo (cfr. al respecto, por ejemplo, James S. Fishkin, 1984). 


\section{BIBLIOGRAFÍA}

Alexy, Robert (1989), «On Necessary Relations Between Law and Morality», en Ratio Juris, vol. 2, núm. 2, julio.

Austin, John(1954), The Province of Jurisprudence Determined, Weidenfeld and Nicolson, Londres.

Bobbio, Norberto (1962), "Giusnaturalismo e positivismo giuridico», en su versión castellana de Ernesto Garzón Valdés en Norberto Bobbio, El problema del positivismo jurídico, EUDEBA, Buenos Aires, 1965.

Bunge, Mario (1989), Treatise on Basic Philosophy-The Good and the Right, vol. 8, D. Reidel Publishing Company, Dordrecht/ Boston/Lancaster.

Fishkin, James S. (1984), Beyond Subjective Morality-Ethical Reasoning and Political Philosophy, Yale University Press, New Haven/Londres.

Garzón Valdés, Ernesto (1987), El concepto de estabilidad de los sistemas políticos, Centro de Estudios Constitucionales, Madrid.

Hart, H. L. A. (1958): «Legal and Moral Obligation», en A. I. Melden (ed.), Essays in Moral Philosophy, Seatle.

(1961), The Concept of Law, Clarendon Press, Oxford.

(1982), Essays on Bentham-Jurisprudence and Political Theory, Clarendon Press, Oxford.

Hedenius Ingemar (1981), «On relativism in ethics», en Theoria, vol. XLVII, Parte 3.

Hoerster, Norbert (1989), Verteidigung des Rechtspositivismus, Neuwied/ Francfort.

Kelsen, Hans (1948), «Law, State and Justice in the Pure Theory of Law», en Yale Law Journal, 57.

Klug, Ulrich (1989), Problemas de la filosofía y de la pragmática del derecho, traducción de Jorge M. Seña, Alfa, Barcelona.

Laun, Rudolf (1935), Recht und Sittlichkeit, Berlin.

Lipset, Seymour M. (1959), «Some Social Requisites of Democracy: Economic Development and Political Legitimacy», en American Political Science Review, 53 (marzo 1959).

Luhmann, Niklas (1975), Legitimation durch Verfahren, Darmstadt/Neuwied.

MacCormick, Neil (1981), H. L. A. Hart, Edward Arnold (Publishers) Ltd., Londres.

Radbruch, Gustav (1956), Rechtsphilosophie, 5. a edición, K. F. Koehler Verlag, Sttutgart. 
Sartorius, Rolf (1987), «Positivism and the Foundations of Legal Authority», en Ruth Gavison (ed.), Issues in Contemporary Legal Philosophy-The Influence of H. L. A. Hart, Clarendon Press, Oxford.

Shuman, Samuel I. (1963), Legal Positivism-Its Scope and Limitations, Wayne State University Press, Detroit.

Soper, Philip (1989), «Legal Theory and the Claim of Authority», en Philosophy \& Public Affairs, vol. 18, núm. 3, págs. 209-237.

Viehweg, Theodor (1960), «Über den Zusammenhang zwischen Rechtsphilosophie, Rechtstheorie und Rechtsdogmatik», en Estudios Jurídico-sociales-Homenaje al profesor Luis Legaz y Lacambra, Santiago de Compostela.

Wittgenstein, Ludwig (1960), «Philosophische Untersuchungew», en Schriften, Suhrkamp Verlag, Francfort.

Zimmerling, Ruth (1989), «Necesidades básicas y relativismo moral», en Doxa, 7, 1990. 